\title{
PERAN SEMANTIS PRONOMINA DALAM BAHASA MANDAR
}

\section{THE SEMANTICS ROLE OF PRONOUN IN MANDARESE}

\author{
Jerniati I. \\ Balai Bahasa Provinsi Sulsel dan Provinsi Sulbar \\ Jalan Sultan Alauddin Km 7, Tala Salapang, Makassar \\ Telepon 0411-882401, Faksimil 0411-882403, Pos-el jerni_indra@yahoo.co.id
}

\begin{abstract}
This research analysed the semantics role of pronoun in Mandarese from structural morphology perspective. This research aims to describesemantics role of pronoun in Mandarese. It used descriptive qualitative method, data collecting byelicitation technique, recording and noting, and documentation analysis. Oral data were gained from native speakers and writing data were got from Mandarese folklore and relevant researchs. The analysis of reality showed three semantics roles that can be functioned by pronoun in Mandarese sentences, namely 1) agentifrole in forms of free, active, and passive, 2) goals role, dan 3) locative role.
\end{abstract}

Key words:semantics role, pronoun, Mandarese

\begin{abstract}
Abstrak
Penelitian ini mengkaji peran semantis pronomina bahasa Mandar ditinjau dari perspektif morfologi struktural. Penelitian ini bertujuan medeskripsikan peran semantis pronomina bahasa Mandar. Kajian ini menggunakan metode deskriptif kualitatif, pengumpulan data dilakukan dengan teknik elisitasi, perekaman, dan pencatatan, serta analisis dokumentasi. Data lisan diperoleh dari penutur asli dan data tertulis dari buku-buku cerita rakyat berbahasa Mandar serta hasil-hasil penelitian yang relevan. Realitas kajian menunjukkan ada tiga peran semantis yang dapat diemban oleh pronomina dalam kalimat bahasa Mandar, yaitu 1) peran pelaku (agentif) bentuk bebas, bentuk aktif, dan bentuk pasif, 2) peran sasaran, dan 3) peran lokatif.
\end{abstract}

Kata kunci: peran semantis, pronomina, bahasa Mandar

\section{Pendahuluan}

Bahasa Mandar adalah salah satu bahasa daerah yang dahulu ada di Sulawesi Selatan, Pada tahun 2004 masyarakat Mandar ingin berdiri sendiri, sehingga terbentuklah Provinsi Sulawesi Barat. Dengan demikian, pendukung bahasa Mandar secara langsung berada pada wilayah tersebut. Oleh karena menggunakan dialek Majene sebagai objek kajian. Pemilihan dialek ini dengan pertimbangan bahwa dialek ini pada umumnya dipakai oleh masyarakat yang berdiam di Kabupaten Majene dan dianggap representatif sebagai daerah sampel, karena bahasa Mandar yang digunakan oleh masyarakat di tempat itu adalah bahasa Mandar yang kurang mendapat pengaruh dari luar.

Penelitian bahasa Mandar telah banyak dilakukan mulai dari tataran fonologi, morfologi, sintaksis 
sampai wacana. Hasil penelitian tersebut ada yang sudah terbit, ada juga yang belum atau masih berupa naskah.

Untuk melengkapi hasil penelitian bahasa Mandar yang membahas morfologi khususnya bentuk kata, pada kesempatan ini penulis memilih salah satu bentuk atau jenis kata, yaitu pronomina, khusus masalah peran semantis pronomina.

Suatu unsur bahasa dapat menduduki peran semantis sesuai dengan kenyataan atau perwujudan yang dinyatakan dalam predikasi suatu klausa atau kalimat dalam tataran fungsi semantis. Peran ini menjeskan tugas apa yang harus dipegang suatu unsur yang terlihat dalam suatu perikeadaan yang dinyatakan predikasi tempat unsur-unsur itu muncul. Oleh karena itu, pronomina dapat berperan sebagai pelaku, sasaran, penerima, pemeroleh, penderita, waktu, dan tempat.

Berdasar pada latar belakang tersebut masalah pokok yang akan dibahas dalam kajian ini, yakni bagaimanakah peran semantis pronomina dalam kalimat bahasa Mandar?

\section{Kerangka Teori}

Kerangka teori yang digunakan sebagai landasan kerja dalam penelitian ini adalah kerangka teori yang berdasarkan linguistik struktural. Teori tersebut yang memandang bahasa itu sebagai unit-unit yang tersusun, baik secara linear (sintagmatik) maupun secara asosiatif (paradigmatis). Senada dengan Chaer (2003: 346) yang menyatakan bahwa linguistik struktural berusaha mendeskripsikan suatu bahasa berdasarkan ciri atau sifat khas yang dimiliki bahasa itu. Begitupula Kridalaksana (2008:146) mengatakan bahwa linguistik struktural adalah pendekatan yang menganggap bahasa yang menganggap bahasa sebagai sistem yang bebas.

Pronomina dalam sistem kategori atau klasifikasi kata dapat digolongkan sebagai subkategori nomina. Alwi dkk. (2003: 249) menyatakan bahwa pronomina adalah kata yang dipakai untuk mengacu kepada nomina lain. Kategori persona merupakan salah satu kategori yang relevan untuk penerima pronomina. Kategori pronomina ini berhubungan dengan pembedaan para pemeran yang terlibat dalam suatu peristiwa ujaran ke dalam tiga subkategori, yakitu persona pertama, yang digunakan oleh pembicara untuk mengacu kepada diri sendiri sebagai subjek, persona kedua yang digunakan oleh pembicara untuk mengacu kepada pendengar, atau yang diajak bicara (lawan bicara), dan pesona ketiga yang digunakan oleh pembicara untuk mengacu kepada orang atau benda yang tidak termasuk pembicara atau pendengar.

Ciri pronomina secara umum adalah acuannya yang dapat berpindah-pindah karena bergantung kepada siapa yang menjadi pendengar atau pembaca, dan siapa/apa yang dibicarakan. Pronomina juga dapat dikenal berdasarkan ciri fonologis, cirimorfologis, ciri sintaksis, dan ciri semantiknya.

\section{Metode}

Penelitian ini menggunakan metode deskriptif untuk menggambarkan pronomina bahasa Mandar secara empiris berdasarkan situasi atau fakta yang ada di lapangan dan dipaparkan dengan apa adanya (Sudaryanto, 1988). Metode ini ditunjang dengan teknik elisitasi, perekaman, dan pencatatan, serta analisis dokumentasi.

Teknik elisitasi dimanfaatkan untuk memancing (merespon) pemakai bahasa penutur asli yang dijadikan sebagai informan dengan cara mengajukan pertanyaan dengan terarah mengenai objek penelitian yakni pronomina bahasa Mandar. Sehubungan dengan itu, informan diharapkan memberikan reaksi berupa ujaran atau jawaban yang berkaitan dengan objek kajian tersebut.

Teknik perkaman dimanfaatkan agar data lisan dapat terjaring dengan baik. Rekaman ujaran spontan dilakukan dengan tidak mempersoalkan masalah yang dibicarakan, sedangkan rekaman pilihan dilakukan dengan cara memuculkan suatu masalah kepada informan kemudian melakukan perekaman.

\section{Pembahasan}

Berdasar bentuknya pronomina bahasa Mandar dapat dibedakan atas pronomina persona, pronomina penunjuk, dan pronomina penanya. Ketiga pronomina tersebut diuraikan sebagai berikut. 


\section{1) Pronomina Persona}

Pronomina persona adalah pronomina yang dipakai untuk mengacu ke pada orang. Dalam peran komunikasi, pronomina persona dapat mengacu pada diri sendiri (sebagai pihak pertama), mengacu pada orang yang diajak bicara (pihak kedua), dan yang mengacu pada orang yang dibicarakan (pihak ketiga). Dengan demikian, pronomina persona dibedakan atas persona pertama, persona kedua, dan persona ketiga, masing-masing dalam bentuk tunggal dan jamak.

\section{Bagan 1}

\begin{tabular}{|l|l|l|}
\hline Pronomina Persona & Tunggal & Jamak \\
\hline Pertama & yau 'saya' & yamiq 'kami' \\
\hline Kedua & iqo 'engkau' & $\begin{array}{l}\text { iqo nasang 'kamu semua } \\
\text { iqo mieq 'kamu semua' } \\
\text { itaq nasang 'kita semua' }\end{array}$ \\
\hline Ketiga & ia 'dia' & seqia 'mereka' \\
\hline
\end{tabular}

\section{Peran Pelaku (Agentif) Bentuk Bebas}

Dalam bahasa Mandar pronomina persona bentuk bebas yang berperan sebagai pelaku adalah yau 'saya', iqo 'engkau', yamiq 'kami', itaq 'anda', ia 'ia', dan seqia 'mereka'.

Contoh:

1) Yau mikkeqde di baqba 'saya berdiri di pintu'

(Saya berdiri di pintu)

2) Iqo musti lumamba mambawa diqe suraqe 'kamu mesti pergi membawa ini surat ini' (Engkau mesti pergi membawa surat ini)

3) Yamiq mambawa diqo loka 'kami membawa itu pisang' (Kami yang mambawa pisang itu)

4) Itaq naperoa mamba 'kita dipanggil pergi' (Anda yang dipanggil pergi)

5) Ia pole dionging 'ia datang kemarin' (Ia yang datang kemarin)

6) Seqia mandoeq di lembang 'mereka mandi di sungai'

(Mereka mandidi sungai)

Unsur-unsur yau, iqo, yamiq, itaq, ia, dan seqia dalam kalimat (1-6) merupakan pronomina yang berperan sebagai pelaku, karena melakukan tindakan yang dinyatakan oleh predikat pada kalimat $(1-6)$.

\section{Peran Pelaku (Agentif) BentukAktif}

Pronomina persona bahasa Mandar yang menduduki peran pelaku adalah pronomina persona bentuk enklitik (-aq, $-u,-i$, nasangoqo, dan nasangi) yang berpadu dengan verba aktif dan berfungsi sebagai subjek dalam tataran sintaksis.

Contoh:

7) manulis $+-a q \longrightarrow$ manulisaq (suraq) 'menulis' 'saya' 'saya menulis surat'

8) manbaca $+-o \longrightarrow$ mambacao (suraq) 'membaca' 'engkau' 'engkaumembaca surat' mamba $+-\mathrm{i} \longrightarrow$ mambai (massikola) 'pergi' 'dia' 'dia pergike sekolah'

9) maande +nasangi $\rightarrow$ mande nasangi (kande-kande)

'makan' 'semua dia' 'mereka makan kue'?

10) maqirrangngi+nasangoq $\longrightarrow$

maqirrangnginasangoqo radio.

'dengar' 'semua kamu' 'kalian mendengarkan radio'

Unsur - aq,yang berpadu dengan verba aktif manulis menjadi manulisaq dan unsur $-o$ yang berpadu dengan verba aktif mambaca,menjadi mambacao, serta unsur - $i$ yang berpadu dengan 
verba aktif mamba menjadi mambai. Begitupula dengan nasangoqo, dan nasangiunsur -o pada kata nasangoqo dan - $i$ pada kata nasangi. Unsur-unsur tersebut merupakan pronomina persona bentuk enklitik yang menduduki peran sebagai pelaku dalam contoh kalimat (7-10).

\section{Peran Pelaku (Agentif) Bentuk Pasif}

Pronomina persona yang menduduki peran pelaku bentuk pasif adalah pronomina persona bentuk proklitik $u$-, $m u$-, dan $n a$ - yang dalam fungsi sintaksisnya menduduki fungsi subjek.

Contoh:

11) $u^{-}+$baca $\longrightarrow$ (suraqmu) ubaca

'(suratmu) saya baca'

(Suratmu telah saya baca)

12) $m u-+$ janji $\longrightarrow$ mujanji (doiq)

'engkau menjanjikan uang'

(Engkau menjanji dia uang)

14) na- + tarima $\longrightarrow$ natarimai (surakna)

'diterima sudah (suratnya)'

(Sudah dia terima suratnya)

Unsur $u-, m u-, n a-$, pada kalimat tersebut dalam tataran semantik berfungsi sebagai peran pelaku, karena unsur-unsur tersebut melakukan tindakan yang dinyatakan oleh predikat. Unsur ini dalam tataran fungsi sintaksis merupakan subjek pada kalimat tersebut.

\section{Peran Sasaran}

Pronomina persona yang dapat menduduki peran sasaran adalah pronomina persona bentuk enklitik $a q$, $-o$, dan $-i$ yang dalam fungsi sintaksisnya menduduki fungsi subjek. Peran sasaran yang dimaksud di sini boleh menderita, penerima atau pun peserta yang dinyatakan oleh predikat.

Contoh:

15) Naalliangaq boyang baru kamaqu 'dibelikan saya rumah baru ayahku' (Saya dibelikan rumah baru oleh ayahku)

16) Nakiringangoqo suraq kamaqmu 'dikirimi kamu surat ayahmu' (Engkau yang dikirimi surat oleh ayahmu)
17) Naoppoangi baqba kindoqna 'ditutupkan dia pintu oleh ibunya'

(Dia ditutupkan pintu oleh ibunya)

\section{Peran Lokatif}

Pronomina persona yang dapat berperan lokatif ialah pronomina persona yang menyatakan makna tempat, yaitu tempat terjadinya atau berlakunya peristiwa yang dinyatakan oleh predikat, tempat yang dituju atau arah sebagai jawaban pertanyaan ke mana atau dimana.

Contoh

18) Miccoeaq di itaq

'mengikut saya di anda'

(Saya mengikut kepada anda)

19) Mepului lao di yau

'mengadu ia di saya'

(Ia mengadu kepada saya)

20) Diang inrangngu lao di ia

'ada utang saya di dia'

(Saya berutang kepadanya)

Pronomina persona yang menyatakan peran lokatif pada kalimat (18-20) dapat diketahui oleh adanya kata depan $d i$ 'kepada' dalam kalimat tersebut. Frasa di itaq 'kepada anda' di yau 'kepada saya' dan di ia 'kepada dia/nya' menduduki fungsi keterangan dalam kalimat dengan peran lokatif. Peran lokatif tersebut berarti tempat yang digunakan untuk melakukan suatu tindakan yang dinyatakan oleh predikatnya.

\section{Pronomina Penanya}

Pronomina penanya adalah kategori yang dipakai sebagai pemarkah pertanyaan yang berfungsi menggantikan sesuatu yang ingin diketahui oleh si pembicara atau menjelaskan sesuatu yang telah diketahui si pembicara.

Pronomina penanya sesuai dengan namanya berkaitan dengan pertanyaan. Dari segi makna yang ditanyakan itu dapat mengenai orang, barang, atau pilihan. Pronomina penanya dalam bahasa Mandar yang terjaring dalam penelitian ini adalah inai 'siapa', apa 'apa', inna 'mana, di mana', mangapa 'me- 
ngapa', pirang 'kapan, bilamana', dan meqapa 'bagaimana'.

\section{Peran Semantis Pronomina Penanya}

Apabila dilihat dari fungsi semantis, maka pronomina penanya dapat mengacu kepada orang, barang, atau pilihan, dan sebagainya. Berikut ini dijelaskan pronomina penanya sesuai dengan maknanya.

\section{Apa 'apa'}

Pronomina penanya apa secara semantis dipergunakan untuk menanyakan benda, hal, dan binatang. Contoh:

21) Apa napogauq i Ali? 'apa dikerjakan si Ali?' (Apa yang dikerjakan oleh Ali?)

22) Apa napiara kamaqmu? 'apa dipelihara ayahmu?' (Apa yang dipelihara oleh ayahmu?)

23) Apa puramoqo miqguru? 'apa sudah kamu belajar?' (Apa kamu sudah belajar?)

24) Allo apa namambao? 'hari apa pergi kamu?' (Hari apa kamu pergi?)

25) Apa meloq mualli? 'apa mau kamu beli?' (Apa yang kamu mau beli?)

\section{Inai 'siapa'}

Pronomina penanyainai 'siapa' secara semantis dipergunakan untuk menanyakan orang.

Contoh:

27) Inai pole dionging? 'siapa datang kemarin?' (Siapa yang datang kemarin?)

28) Inai mambeio baju? 'siapa memberi kamu baju?'

(Siapa yang memberikan baju kepada kamu?)
29) Inai sangana kandiqmu? 'siapa namanya adikmu?' (Siapa nama adikmu?)

30) Inai musolangang pole? 'siapa kamu temani datang?' (Siapa yang datang bersamaa kamu?)

31) Inai nasialang? 'siapa dia saling ambil?' (Dengan siapa dia menikah?)

\section{Inna 'mana'}

Pronomina penanyainna'mana' secara semantik dipergunakan untuk menanyakan suatu pilihan tentang barang, orang atau hal.

Contoh

32) Inna boyangmu? 'mana rumahmu?'

(Dimana rumahmu?)

33) Inna pona anjoromu? 'mana pohon kelapamu?' (Yang mana pohon kelapamu?)

34) Inna kandiqmu? 'mana adikmu?' (Yang mana adikmu?)

Selain itu pronomina inna 'mana' dapat pula dipakai untuk menanyakan tempat berada, tempat yang dituju, dan tempat yang ditinggalkan.

Contoh

35) Inna naingei i Ali mottong di teqe? 'mana tempatnya siAli tinggal sekarang?' (Ali tinggal di mana sekarang?)

36) Madondong i Ali inna nanaola? 'besok si Ali ke mana akan pergi?' (Besok Ali akan pergi kemana?)

37) Pole innai I Ali? 'datang dari mana si Ali?' (Ali datang dari mana?) 


\section{Mangapa 'mengapa'}

Pronomina penanya mangapa 'mengapa' secara semantis digunakan untuk menanyakan sebab terjadinya sesuatu.

Contoh:

38) Mangapai natalaqo pole?

'Mengapa terlambat kamu datang?'

(Mengapa kamu dating terlambat?)

39) Mangapa na andiango mamba massikola? 'Mengapa tidak kamu pergi ke sekolah?'

(Mengapa kamu tidak berangkat ke sekolah?)

40) Mangapai $i$ kandiq na andiangi ummande? 'Mengapa si adik tidak ia makan?'

(Mengapa adik tidak makan?)

\section{Pirang 'kapan'}

Pronomina penanya pirang 'kapan' secara semantis dipergunakan untuk menanyakan waktu terjadinya suatu peristiwa. Kata pirang 'kapan' biasanya muncul bersama partikel pai, pao, dan paq.

Contoh:

41) Pirang pai meakkeq?

'Kapan nanti ia berangkat?'

(Kapan ia akan berangkat?)

42) Pirang pao pole?

'Kapan nanti kamu datang?'

(Kapan kamu akan datang?)

43) Pirang paq mamba?

'Kapan nanti saya pergi?'

(Kapan saya akan pergi?)

\section{Meqapa 'bagaimana'}

Pronomina penanya meqapa'bagaimana' secara semantis dipergunakan untuk menanyakan sesuatu atau cara untuk melakukan perbuatan.
Contoh

44) Meqapai tomawuwemmu di teqe?

'Bagaimana orang tuamu sekarang?'

(Bagaimna keadaan orang tuamu sekarang?)

45) Meqapai carana mappapia lopi?

'Bagaimana caranya membuat perahu?'

(Bagaimana caranya membuat perahu?)

46) Meqapai atuo-tuonna to mabubenna?

'Bagaimana kehidupan-kehidupannya orang tuanya?'

(Bagaimana kehidupan orang tuanya?)

\section{Saqapa 'berapa'}

Pronomina penanya saqapa 'berapa' secara semantis dipergunakan untuk menanyakan jumlah, ukuran takaran, nilai, harga, dan jangka waktu.

Contoh

47) Saqapa allianna diqe baju?

'berapa harganya ini baju?'

(Baju ini harga berapa?)

48) Saqapami anaqta?

'berapa sudah anak anda?'

(Anaka Anda sudah beapa?)

49) Pukul saqapa napoleo madondong?

'pukul berapa datang kamu besok?'

(Pukul berapa kamu datang besok?)

\section{Pronomina Penunjuk}

Pronomina penunjuk atau demonstrativa adalah kategori yang berfungsiuntuk menunjukkan sesuatu benda, tempat dan waktu yang berada di dalam atau di luar tuturan. Dalam bahasa Mandar pronomina penunjuk dapat dibagi atas tiga macam, yaitu 1) pronomina penunjuk umum yaitu,diqe 'ini', diqo'itu' , dan anu 'anu' 2) pronomina penunjuk tempat, yaitu dini 'disini', dan dio'disitu' dan 3) pronomina penunjuk ihwal, yaitu bassa diqe 'begini', dan bassa diqo 'begitu'. 


\section{Peran Semantis Pronomina Penunjuk}

Apabila dilihat dari fungsi semantis pronomina penunjuk hanya dapat mengacu pada tempat atau lokatif. Berikut ini dijelaskan pronomina penunjuk sesuai dengan maknanya.

50) Diqe bukuqu uitai.

'ini bukuku kucari'

(Ini bukuku yang kucari.)

51) Diqo sanaqeke manarang sannaq mangaji. 'itu anak pintar sekali mengaji.'

(Anak itu pintar sekali mengaji)

Pronomina diqe dan diqo pada contoh (4950) merupakann pronomina yang berperan semantis menunjuk tempat.Pronomina penunjuk yang menyatakan hal tersebut dapat diketahui karena adanya kata depan diqe 'ini' dan diqo 'itu' dalam kalimat tersebut. Frasa diqo bukuqu 'itu bukuku'diqe sanaqeke 'ini anak'. Peran lokatif itu menunjuk tempat atau benda yang dikenai suatu tindakan.

\section{Simpulan}

Berdasar pada uraian terdahulu disimpulkan bahwa pronomina bahasa Mandar ada tiga, yaitu pronomina persona, pronomina penunjuk, dan pronomina penanya. Peran semantis pronomina yang terdapat dalam bahasa Mandar ada tiga macam, yaitu 1) peran pelaku (agentif) bentuk bebas yaitu yau'saya', iqo 'kamu', seqiya 'mereka' yamiq 'kami'. Peran pelaku bentuk aktif, yaitu (-aq, $-u,-i$, nasangoqo, dan nasangi) dan peran pelaku bentuk pasif adalah pronomina persona bentuk proklitik, yaitu $u$-, $m u$-, dan $n a-.2)$ peran sasaran adalah pronomina persona bentuk enklitik - $a q,-o$, dan $-i, 3$ ) peran lokatif yaitu $d i$ 'di/kepada', yang merupakan pronomina penunjuk diqo 'itu' dan diqe 'ini', dini/indini 'disini' dan dio/indio 'disitu'.

\section{Daftar Pustaka}

Alwi, Hasan et al. 1998. Tata Bahasa Baku Bahasa Indonesia. Jakarta: Balai Pustaka.

Ba'dulu, Abd. Muis. 1980. Struktur Morfologi dan Sintaksis Bahasa Mandar. Jakarta: Pusat Pembinaan dan Pengembangan Bahasa.

—, 2002. "Pembentukan Kata Bahasa Indonesia Suatu Kajian Morfologi Generatif'. Makassar: Program Pascasarjana Universitas Negeri Makassar.

Cahyono, B. 1995. Kristal-Kristal Ilmu Bahasa. Surabaya: Airlangga University Press.

Elson, B.and Picket. 1987. Beginning Morphology and Syntax. Mexico City: SIL.

Kentjono, Djoko. 1990. Dasar-Dasar Linguistik Umum. Jakarta: Fakultas Sastra Universitas Indonesia.

Kridalaksana, Harimurti. 2008. Kamus Linguistik. Jakarta: PT Gramedia.

Muthalib Abd. 1977. Kamus Bahasa MandarIndonesia. Jakarta: Pusat Pembinaan dan Pengembangan Bahasa, Departemen Pendidikan dan Kebudayaan.

Muthalib Abd. et al. 1992. Tata Bahasa Mandar. Jakarta: Pusat Pembinaan dan Pengembangan Bahasa.

Pike, K. L. 1992. Konsep Linguistik; Pengantar Teori Tagmemik. Diterjemahkan oleh Kenjanawati Gunawan. Jakarta: PT Gelora Aksara Pratama.

Samsuri. 1994. Analisis Bahasa. Jakarta: Erlangga. Scalise, Segio. 1983. Generative Morphology. Dorrech-hallad: Foris Publications.

Sugono, Dendy. et al. 2008. Kamus Besar Bahasa Indonesia (Edisi ke-4). Jakarta: Balai Pustaka. 
